\title{
Corrigendum: Seasonal Dynamics in Dissolved Organic Matter, Hydrogen Peroxide, and Cyanobacterial Blooms in Lake Erie
}

\author{
Rose M. Cory ${ }^{1 *}$, Timothy W. Davis ${ }^{2}$, Gregory J. Dick ${ }^{1,3}$, Tom Johengen ${ }^{4}$, Vincent J. Denef ${ }^{3}$, \\ Michelle Berry ${ }^{3}$, Sarah E. Page ${ }^{1+}$, Susan B. Watson ${ }^{5}$, Kate Yuhas ${ }^{1}$ and George W. Kling ${ }^{3}$ \\ ${ }^{1}$ Department of Earth and Environmental Sciences, University of Michigan, Ann Arbor, MI, United States, ${ }^{2}$ Great Lakes \\ Environmental Research Laboratory, National Oceanic and Atmospheric Administration, Ann Arbor, MI, United States, \\ ${ }^{3}$ Department of Ecology and Evolutionary Biology, University of Michigan, Ann Arbor, MI, United States, ${ }^{4}$ Cooperative \\ Institute for Limnology and Ecosystems Research, Ann Arbor, MI, United States, ${ }^{5}$ Canada Centre for Inland Waters, \\ Environment and Climate Change Canada, Burlington, ON, Canada
}

Keywords: hydrogen peroxide, Lake Erie, cyanobacteria, Microcystis aeruginosa, microcystins, harmful algal blooms, Great Lakes, CDOM

\section{A corrigendum on}

Edited and reviewed by: Leanne C. Powers, Chesapeake Biological Laboratory, United States

${ }^{*}$ Correspondence: Rose M. Cory rmcory@umich.edu

${ }^{\dagger}$ Present Address: Sarah E. Page Arcadis U.S., Inc., Minneapolis, MN United States

Specialty section

This article was submitted to Marine Biogeochemistry,

a section of the journal Frontiers in Marine Science

Received: 09 October 2017 Accepted: 09 November 2017 Published: 21 November 2017

Citation:

Cory RM, Davis TW, Dick GJ, Johengen T, Denef VJ, Berry M, Page SE, Watson SB, Yuhas $K$ and Kling GW (2017) Corrigendum:

Seasonal Dynamics in Dissolved Organic Matter, Hydrogen Peroxide, and Cyanobacterial Blooms in Lake

Erie. Front. Mar. Sci. 4:377. doi: 10.3389/fmars.2017.00377

\section{Seasonal Dynamics in Dissolved Organic Matter, Hydrogen Peroxide, and Cyanobacterial Blooms in Lake Erie \\ by Cory, R. M., Davis, T. W., Dick, G. J., Johengen, T., Denef, V. J., Berry, M. A., et al. (2016). Front. Mar. Sci. 3:54. doi: 10.3389/fmars.2016.00054}

In the original article, there was a spreadsheet error in the calculation of hydrogen peroxide $\left(\mathrm{H}_{2} \mathrm{O}_{2}\right)$ concentrations in Lake Erie. Hydrogen peroxide concentrations were measured using the Amplex Red method, which requires subtraction of the background reagent signal from all samples and standards. Subtraction of background reagent signal was not done when reporting hydrogen peroxide concentrations in the original manuscript; this error has now been corrected. Corrected hydrogen peroxide concentrations are lower than reported in the paper by a factor of 1.8 (i.e., original $\mathrm{H}_{2} \mathrm{O}_{2} / 1.8$ = corrected $\mathrm{H}_{2} \mathrm{O}_{2}$ ). Corrected $\mathrm{H}_{2} \mathrm{O}_{2}$ concentrations are significantly, linearly correlated with the originally reported $\mathrm{H}_{2} \mathrm{O}_{2}$ concentration $\left(p<0.001, R^{2}=0.8\right.$, slope $=1.8$ \pm 0.04 ). Thus, the temporal and spatial patterns in $\mathrm{H}_{2} \mathrm{O}_{2}$ concentrations reported in Lake Erie in Figures 7D, 10D, 11 remain the same, but the hydrogen peroxide concentrations reported in Figures $3,4 \mathrm{D}, 8 \mathrm{C}, 10 \mathrm{D}, 11,13$ are lower by a factor of 1.8 . Corrected $\mathrm{H}_{2} \mathrm{O}_{2}$ concentrations were within measurement error of the original reported concentration for $12 \%$ of the Lake Erie samples, while $88 \%$ of the corrected $\mathrm{H}_{2} \mathrm{O}_{2}$ concentrations were significantly lower than the original, reported concentration.

Corrected text is reported here. In the abstract and results section, the text below replaces the original text from the published manuscript with the only difference being the corrected $\mathrm{H}_{2} \mathrm{O}_{2}$ concentrations. In the discussion and conclusions sections, minor revisions were made to sentences in the published manuscript (shown below) to provide a more conservative interpretation of the relative importance of biological activity to $\mathrm{H}_{2} \mathrm{O}_{2}$ concentrations. That is, given the lower $\mathrm{H}_{2} \mathrm{O}_{2}$ concentrations after correction, photochemical processes of CDOM may account for a larger fraction of $\mathrm{H}_{2} \mathrm{O}_{2}$ than originally assessed. However, the main conclusion of the paper remains the same: that biological activity likely contributed substantially to $\mathrm{H}_{2} \mathrm{O}_{2}$ concentrations in Lake Erie. 


\begin{abstract}
:
"Concentrations of $\mathrm{H}_{2} \mathrm{O}_{2}$ in Lake Erie ranged from $2 \pm 24 \mathrm{nM}$ to $1140 \pm 240 \mathrm{nM}$ (average of $162 \pm 11 \mathrm{nM} ; n=221$ ).
\end{abstract}

Materials and Methods, Section $2.6 \mathrm{H}_{2} \mathrm{O}_{2}$ Concentrations, Paragraph Number 1:

Results, Section $3.4 \mathrm{H}_{2} \mathrm{O}_{2}$ Concentrations in Lake Erie, Paragraph Number 1:

Hydrogen peroxide concentrations in the surface waters of Lake Erie varied by over an order of magnitude during the study period, from $2 \pm 24$ to $1,140 \pm 240 \mathrm{nM}$ (average \pm SE from triplicate measurements of each water sample), with an overall average of $162 \pm 11 \mathrm{nM}$ (average $\pm \mathrm{SE}, n=221$; Figure 10D).

Results, Section $3.4 \mathrm{H}_{2} \mathrm{O}_{2}$ Concentrations in Lake Erie, Paragraph Number 3:

The largest difference in $\mathrm{H}_{2} \mathrm{O}_{2}$ concentration between surface water and depth was observed when $\mathrm{H}_{2} \mathrm{O}_{2}$ at $21 \mathrm{~m}$ was nearly double the surface concentration at the same site under mixed conditions $\left(312 \pm 53 \mathrm{nM}\right.$ vs. $148 \pm 42 \mathrm{nM} \mathrm{H}_{2} \mathrm{O}_{2}$ in bottom vs. surface, respectively at site 949 in the central basin; Figure 8C).

\section{Discussion, Section 4, Paragraph Number 1:}

The average and range of hydrogen peroxide $\left(\mathrm{H}_{2} \mathrm{O}_{2}\right)$ concentrations in Lake Erie $(162 \pm 11 \mathrm{nM}$, up to a maximum of $1,140 \pm 240 \mathrm{nM}$; Table 1 and Figure 10D) were higher than the range previously observed at one station in the western basin of Lake Erie in August 1987 (100-200 nM; Cooper et al., 1989), but within the wide range of $\mathrm{H}_{2} \mathrm{O}_{2}$ concentrations observed in lakes ( $~ 10 \mathrm{nM}$ to $>2 \mu \mathrm{M}$; (Cooper and Zika, 1983; Cooper et al., 1989; Häkkinen et al., 2004; Febria et al., 2006; Khan et al., 2013; Scully et al., 1996).

Discussion, Section 4, Paragraph Number 2:

Using the average calculated photochemical production rate of $67 \pm 3 \mathrm{nM} \mathrm{h}^{-1} \mathrm{H}_{2} \mathrm{O}_{2}$ by CDOM, it would take almost $3 \mathrm{~h}$ of mid-day light to produce the observed average concentration of $\mathrm{H}_{2} \mathrm{O}_{2} \quad(162 \pm 11 \mathrm{nM})$ assuming no other sources and no sinks. All water samples were collected between 09:00 to $15: 30 \mathrm{~h}$, with the majority of samples collected between $10: 00 \mathrm{~h}$ and $12: 30 \mathrm{~h}$, suggesting that there could have been sufficient time and UV light for photochemical production to generate the observed concentrations if $\mathrm{H}_{2} \mathrm{O}_{2}$ sinks were minimal.

\section{Discussion, Section 4, Paragraph Number 3:}

Photochemical production of $\mathrm{H}_{2} \mathrm{O}_{2}$ by CDOM could account for the observed $\mathrm{H}_{2} \mathrm{O}_{2}$ if CDOM in the lake consistently had $\sim 3$-fold higher apparent quantum yields $\left(\Phi_{\lambda}\right.$; Equation 3$)$ than we used.

Discussion, Section 4, Paragraph Number 7:

For example, given that the depths of bottom water sampled (4$61 \mathrm{~m}$ ) were also greater than the depth of UV light penetration (depth of $1 \%$ light was $1.5 \pm 0.1 \mathrm{~m}$ for $412 \mathrm{~nm}$ ), there was not enough UV light to produce the $30-300 \mathrm{nM} \mathrm{H}_{2} \mathrm{O}_{2}$ observed at depth (Figure 8C).

However, in this study, similar magnitudes of $\mathrm{H}_{2} \mathrm{O}_{2}$ concentrations were observed between surface and bottom waters even at depths $>20 \mathrm{~m}$ during stratified conditions (Figure $8 \mathrm{C})$.

Conclusions and Implications, Section 5, Paragraph Number 1:

This study demonstrated that CDOM and $\mathrm{H}_{2} \mathrm{O}_{2}$ concentrations were not related and that even the upper estimates of photochemical production of $\mathrm{H}_{2} \mathrm{O}_{2}$ by CDOM were likely too low to account for all $\mathrm{H}_{2} \mathrm{O}_{2}$ (especially at depths below the photic zone). These results, combined with measured and estimated rates of biological production of $\mathrm{H}_{2} \mathrm{O}_{2}$ that can equal or exceed photochemical production (this study; Marsico et al., 2015), strongly suggest that biological activity contributes substantially to $\mathrm{H}_{2} \mathrm{O}_{2}$ concentrations in Lake Erie.

Conflict of Interest Statement: The authors declare that the research was conducted in the absence of any commercial or financial relationships that could be construed as a potential conflict of interest.

Copyright (c) 2017 Cory, Davis, Dick, Johengen, Denef, Berry, Page, Watson, Yuhas and Kling. This is an open-access article distributed under the terms of the Creative Commons Attribution License (CC BY). The use, distribution or reproduction in other forums is permitted, provided the original author(s) or licensor are credited and that the original publication in this journal is cited, in accordance with accepted academic practice. No use, distribution or reproduction is permitted which does not comply with these terms. 